\title{
Trabajo social y ambiente, un escenario para la innovación y la intervención pertinente
}

\section{Social work and its enwironment, a scenario for innovation and relevant intervention}

Nancy Lorena Castrillón", Eliana María Posada Muñoz

Recibido: 25 de noviembre de 2020 / Aceptado: 8 de julio de 2021 / Publicado: 13 de diciembre de 2021

Forma de citar este artículo en APA:

Castrillón, N. L., \& Posada Muñoz, E. M. (2021). Trabajo social y ambiente, un escenario para la innovación y la intervención pertinente. Poiésis, (41), 191-198. https://doi.org/10.21501/16920945.4192

\section{Resumen}

Esta ponencia, es una reflexión del proceso vivido por el semillero de investigación: Ambiente Planeación, Desarrollo y Trabajo Social, durante el periodo 2018-2020-1, desde las investigaciones: Prácticas y saberes de intervención en el escenario ambiental, desde la experiencia de los departamentos de Antioquia y Caldas; y, Aprendizajes para la intervención del Trabajo Social a partir de las prácticas y saberes de los movimientos $y$ organizaciones sociales en el marco de la justicia medio ambiental en Antioquia. Estas experiencias contextualizan al semillero para reconocer la importancia del trabajo social ante las problemáticas ambientales contemporáneas, por ende, la necesidad de incluir en la formación académica y profesional, el tema ambiental; dado el constante deterioro al medio ambiente requiere intervenciones eficaces desde la particularidad de los contextos, para propiciar espacios de participación con las comunidades afectadas, desde las cuales se apueste por el fortalecimiento del tejido social.

\section{Palabras clave:}

Desarrollo comunitario; Educación; Intervención; Medio ambiente; Organizaciones sociales; Tejido social; Trabajo social.

Trabajadora social, Universidad Católica Luis Amigó, Medellín-Colombia. Contacto: Nancy.castrillonpa@amigo.edu.co Trabajadora social, Universidad Católica Luis Amigó (Medellín -Colombia), egresada. Contacto: Eliana.posadamu@amigo.edu.co 0000-0002-6774-3568 


\section{Abstract}

This presentation is a reflection of the process lived by the research group: Environment Planning, Development and Social Work, during the 2018-2020-1 period, from the investigations: Intervention practices and knowledge in the environmental scenario, from the experience of the departments of Antioquia and Caldas; and, Learning for the intervention of Social Work from the practices and knowledge of social movements and organizations within the framework of environmental justice in Antioquia. These experiences contextualize the group to recognize the importance of social work in the face of contemporary environmental problems, therefore, the need to include environmental issues in academic and professional training; Given the constant deterioration of the environment, it requires effective interventions from the particularity of the contexts, to promote spaces for participation with the affected communities, from which commits to the strengthening the social fabric.

\section{Keywords:}

Community development; Education; Intervention; Environment; Social Organizations; Social fabric; Social work. 


\section{Problema o necesidad para sautisfacer}

Los vacíos que se presentan en la formación universitaria del trabajo social, respecto al tema ambiental, lo que puede ser un determinante en las tensiones entre trabajo social y medio ambiente en la intervención. Dado que se requiere tener unas bases sólidas epistemológicas y metodológicas que permitan comprender e interaccionar con las diferentes problemáticas contemporáneas ambientales; que requieren un profesional integral, con compromiso ético.

\section{Población beneficiada}

La población beneficiada de este trabajo son los docentes, estudiantes y profesionales de Trabajo Social.

\section{Introducción}

El semillero de investigación se presenta como un espacio de conocimiento, que posibilitó desde la implementación de la metodología cualitativa con técnicas tales como: entrevistas semiestructuradas, consulta y análisis bibliográfico e intercambios académicos para las investigaciones Prácticas y saberes de intervención del Trabajo Social en el escenario ambiental desde la experiencia de los departamentos Antioquia y Caldas, durante el año 2018; y, Aprendizajes para la intervención del Trabajo Social a partir de las prácticas y saberes de los movimientos y organizaciones sociales en el marco de la justicia medio ambiental en Antioquia , para el período 2019-2020.

En la ponencia Trabajo Social y Ambiente, un escenario para la innovación y la Intervención Pertinente. Semillero de Investigación Ambiente, Planeación, Desarrollo y Trabajo Social, se describen los retos y aprendizajes a los que enfrenta la profesión a nivel ambiental. Así mismo, como lo señalan en su libro Murillo Bonvehí y Buckland (2013), se precisan estos retos como:

Definimos las innovaciones sociales como nuevas ideas (productos, servicios y modelos) que cumplen simultáneamente necesidades sociales y crean nuevas relaciones 0 colaboraciones. Dicho de otro modo, aquellas innovaciones que son buenas para la sociedad y que mejoran la capacidad de la sociedad para actuar. (p. 159)

Resulta importante visibilizar el papel que desempeña el trabajador social desde el ámbito socioambiental, siendo este el movilizador y gestor de acciones encaminadas a la sensibilización y educación de las comunidades impactadas por las diversas actividades económicas que se 
desarrollan en su territorio. Hoy día, está llamado de una manera firme a realizar también acciones de innovación, que causen un impacto en las relaciones con las comunidades y a su vez genere alternativas de solución sustentables en el ambiente.

Por lo tanto, los profesionales en Trabajo Social requieren una formación sólida con contenidos epistemológicos, metodológicos y de innovación en la línea ambiental, el cual le permita reconocer la importancia de los derechos humanos y ambientales de los sujetos implicados en las problemáticas ambientales y de esta forma realizar intervenciones que se focalicen hacia el mejoramiento de las condiciones de vida y recuperación del tejido social desde la capacidad instalada gestada en los espacios de participación comunitaria.

\section{Descurrollo}

Pensar la intervención de lo social en lo ambiental parte como lo plantea Liévano Latorre (2013):

Entender el ambiente no como la ecología sino como la complejidad del mundo (Leff, 2006), se abre el camino para comprender los problemas ambientales que hoy nos aquejan (calentamiento global, destrucción de la capa de 0zono, pérdida de la biodiversidad, entre muchos otros) no como expresiones de un malestar de los sistemas naturales, cuya solución pasa por los adelantos tecnológicos, sino como problemas de otro orden, en los que se involucran diversos elementos que dejan en entredicho las bases de la modernidad: los límites del crecimiento, la insustentabilidad del proceso económico, el fraccionamiento del conocimiento y el cuestionamiento a la concentración de poder del Estado y del mercado. (p. 221)

Hacer un reconocimiento de la problemática que en lo ambiental se presenta, trasciende lo meramente biológico causado por procesos bióticos y abióticos; es también responsabilidad de las dinámicas sociales y los procesos evolutivos que va viviendo la comunidad, los cambios que los mismos tiempos van planteando y la búsqueda de crecimiento, en muchas ocasiones indiscriminado, que no reconoce el valor de lo ambiental, sino que, al contrario, lo sacrifica para lograr sus fines.

Es por esto, que la problemática ambiental, no es pertenencia exclusiva de los profesionales en áreas afines a las ciencias naturales, 0 a los ambientalistas, sino que tiene cabida y con mucha fuerza el profesional en Trabajado Social y la intervención que este puede realizar, desde la innovación social, a partir del pensamiento crítico y creativo para reconocer el trasfondo de dichas problemáticas desde el tejido social, que indiscutiblemente es donde se gestan los grandes conflictos de la misma.

Sin embargo, es posible identificar que existen tensiones en el momento de realizar una intervención desde el trabajo social, ya que se puede "marginar" o "esquematizar" la profesión como algo que está dado para otros campos de la sociedad, desconociendo la riqueza inmensa que la intervención social trae en el ámbito ambiental, pero que no ha logrado posicionarse incluso con los esfuerzos y trabajo arduo de muchos profesionales en esta área. 
La visión de complejidad del mundo como determinante de la problemática ambiental, relaciona de manera clara y directa al Trabajo Social, sin embargo, se encuentra un sesgo que reconoce otras profesiones como las que directamente deben intervenir en estos asuntos; como lo plantea Hoyos Jover y Velásquez Arias (2014):

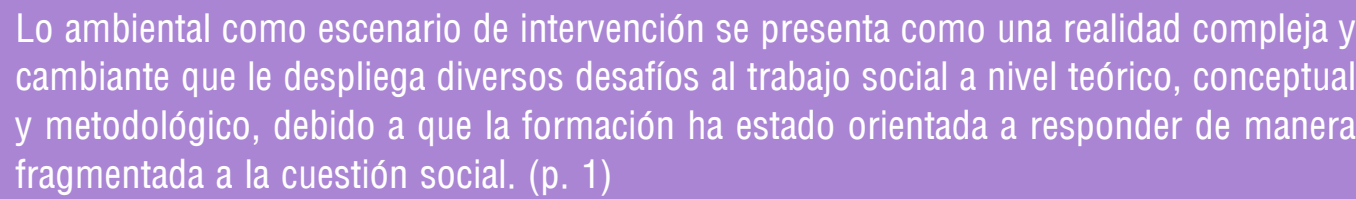

Precisamente en respuesta a la necesidad de abordar la cuestión social de manera integral, es esencial que los profesionales en Trabajo Social emprendan una búsqueda constante de estrategias de intervención alineadas con las dimensiones de la innovación social: la satisfacción de las necesidades humanas, (dimensión de contenido); los cambios en las relaciones sociales, especialmente en lo que respecta a la gobernanza (dimensión de proceso); y aumento de la capacidad sociopolítica y del acceso de los recursos (dimensión de empoderamiento).

Es justamente en la integración de estas tres dimensiones donde frecuentemente se cae en el error de afirmar que la intervención del profesional responde netamente a la satisfacción de los criterios del entramado institucional sobre los intereses, sentires e incluso temores de las comunidades en las que se desarrollan diversas actividades económicas.

Resulta importante que desde la academia se dé mayor validez a la necesidad de integrar la línea ambiental a la profesión de Trabajo Social, lo que permitirá que los procesos de investigación, innovación y desarrollo de conocimiento se alejen de los constantes debates sobre cómo enlazar la teoría y las diversas problemáticas propias de cada territorio, para lograr intervenciones pertinentes con bases sólidas de participación y equidad.

La profesión necesita ser dotada de herramientas con contenido epistemológico desde lo ambiental, lo cual posibilite en los profesionales intervenir en la elaboración de líneas base para la definición de necesidades y problemáticas a las que se pueden asociar los impactos por desarrollo de actividades económicas, las evaluaciones de cumplimiento en licencias ambientales, evaluación del impacto ambiental tanto en la gestión como en la educación ambiental, soberanía y seguridad alimentaria, gestión del recurso hídrico, instrumentos de planificación territorial, planes de desarrollo, políticas públicas en torno al medio ambiente y territorio, entre otros, siendo los campos desde los cuales se pueden generar acciones de intervención e innovación social.

Las comunidades necesitan profesionales capaces de desmitificar a sus integrantes como los sujetos pasivos e incluso inexistentes, para darlos a conocer como los principales actores en lucha por la defensa del territorio, la apropiación de este, la organización autónoma y su condición de sujetos que hacen historia. 
Ahora bien, los vacíos que se encuentran en la formación del Trabajo Social en lo ambiental pueden generar tensiones en la intervención; aquí es pertinente mencionar lo que propone Bojórquez de Grajeda y del Cid García (2014):

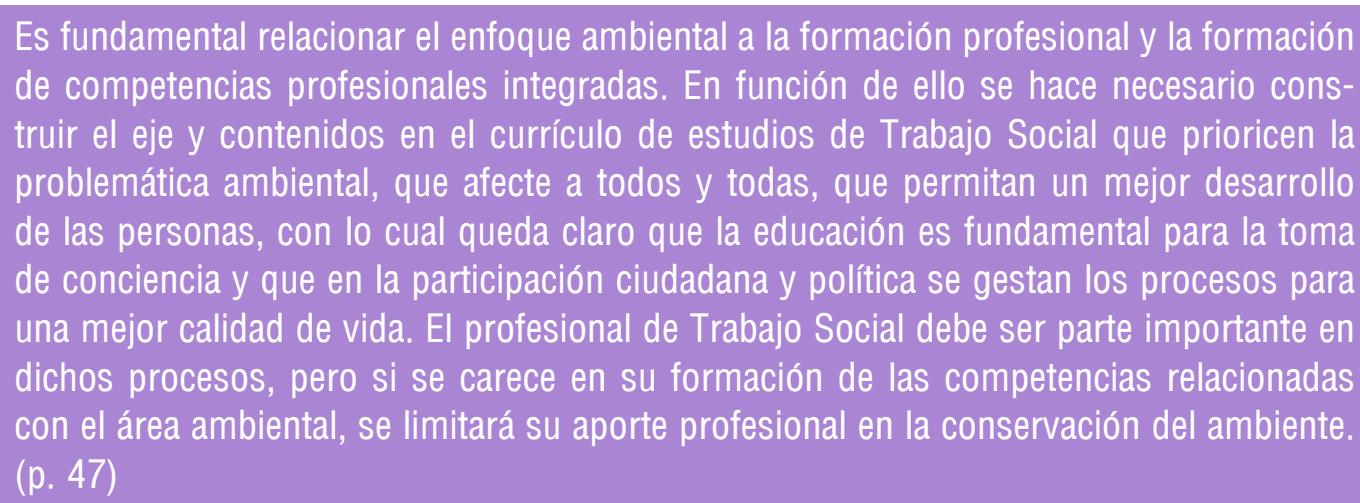

Desde este planteamiento es indispensable que las intervenciones interdisciplinarias desde el área ambiental equilibren el qué, para qué y el cómo de propuestas y proyectos colectivos y creativos que apunten a la garantía de los derechos ambientales de las comunidades que están afectadas en su tejido social; además vincular estas alternativas al mejoramiento de las condiciones de vida de las comunidades, el bienestar social y ambiental de una manera innovadora.

Bajo este contexto el tema ambiental abordado desde el Trabajo Social, aún con su infinidad de aristas, implica el reconocimiento de la primacía de los derechos humanos en sus diversas expresiones y el reconocimiento de la particularidad de los contextos, las lecturas críticas de los actores sociales y sus intereses, con el objetivo de propiciar espacios de fortalecimiento en función de la vinculación a los procesos que se llevan a cabo en su territorio y que afectan a todos por igual.

Otra apuesta que hace el trabajo social desde su intervención es la que se presenta desde las situaciones de explotación de los minerales, lo cual deja grandes impactos en el ambiente y las comunidades.

Es por eso que, el trabajador social debe acompañar en la movilización de las comunidades para que este impacto que se genera sea mitigado y promueva en todos los escenarios una toma de conciencia y responsabilidad no solo de las grandes multinacionales sino de los que allí laboran y sobre todo para que la comunidad no se vea afectada por esta realidad.

Desde este panorama, las comunidades, con capacidad instalada, saberes empíricos y participación, pueden generar debates entre pares que posibiliten espacios de diálogo en los que se formulen conjuntamente propuestas de intervención social en los territorios.

Es así como el trabajador social, está llamado a facilitar procesos de configuración de nuevas comunidades mediante la innovación social. 
Igualmente, el trabajador social debe desarrollar su accionar en la dimensión ambiental dirigido a: asesorar, planear y desarrollar distintos procesos que a nivel investigativo se den en relación con la realidad socioambiental y cultural de las comunidades rurales 0 urbanas con las que entre en contacto.

Dado lo anterior para el proceso educativo de un trabajador social se requieren herramientas que articulen el reconocimiento de las dinámicas comunitarias, los saberes, liderazgos internos, formas para fortalecerlo y la capacidad para generar empatía y sinergia tanto con las comunidades como con la institucionalidad para alcanzar la voluntad favorable que permita vislumbrar el logro de los objetivos planteados en las propuestas de intervención en el ámbito socioambiental.

A lo anterior es importante agregar que en la formación del Trabajo Social se debe tener en cuenta el análisis coyuntural del capitalismo actual y sus manifestaciones en el campo ambiental dado por las desigualdades antagónicas entre las clases sociales, confrontadas entre la pugna por el acceso y manejo de los recursos naturales. Así mismo, es importante tomar conciencia sobre la defensa del ambiente ante los inversionistas y gobiernos locales que no garantizan la equidad en el acceso a los recursos naturales.

De acuerdo con el contexto anterior algunos de los aportes disciplinarios del Trabajo Social, que contribuyen a la gestación de acciones profesionales que se relacionan con perspectivas ambientales como son: participación social y comunitaria, gestión participativa de proyectos, investigación acción participativa y sistematización de experiencias con participación de los sujetos involucrados.

El análisis y comprensión de los problemas ambientales ligados al desarrollo de la industria, la economía y la globalización desmesurada, evidencian cada día más el deterioro ambiental al que estamos expuestos y al cual contribuimos en la mayoría de los casos, conscientemente.

Es por lo que tal deterioro plantea un gran reto para la intervención desde el Trabajo Social, la implementación de prácticas innovadoras enfocadas desde desarrollo sostenible, fortalecimiento de la participación comunitaria y el fomento de una cultura ambiental acertada para cada entorno social, son las bases que desde el actuar de la profesión contrastan con la importancia de los procesos de promoción y educación ambiental.

Bajo esta panorámica se presentan desafíos en la formación de Trabajo Social, por lo cual el semillero ambiente, planeación, desarrollo y trabajo social, ha permitido generar unos espacios de conocimiento, reflexión y aprendizaje desde el ejercicio investigativo.

La investigación que se ha desarrollado en el semillero ha posibilitado el acercamiento y análisis de nuevos términos tales como ecofeminismo, ecología social, justicia medioambiental, relación entre medio ambiente y trabajo social, políticas públicas y aspectos teóricos y prácticos de la intervención desde el trabajo social; esto permite enriquecer el proceso formativo en cuanto al desarrollo 
de una visión integradora de la realidad socioambiental desde los fundamentos teóricos que rigen el accionar del profesional en trabajo social; cimentar desde lo social la toma de conciencia sobre el cuidado y valoración del medio ambiente, es uno de ellos.

Finalmente, se puede concluir que la participación en el semillero permite corroborar la importancia de fortalecer desde la formación académica el tema ambiental, para poder comprender las problemáticas sociales, así como el lugar del Trabajador Social en las contradicciones que se presentan ante las propuestas de desarrollo y las consecuencias que sufren las comunidades; y así construir propuestas de investigación y de intervención acorde con los contextos que conlleven a generar innovación e impactos sociales positivos.

\section{Conflicto de intereses}

Las autoras declaran la inexistencia de conflicto de interés con institución o asociación comercial de cualquier índole.

\section{Referencias}

Arellano-Escudero, N. A. (2014). Intervención socioambiental: intersecciones del Trabajo Social y la institucionalidad ambiental. Revista de Trabajo Social, (91), 3-14. https://doi.org/10.7764/ rts.91.1-11

Bojórquez de Grajeda, M., \& del Cid García, A. P. (2014). Inclusión del enfoque ambiental en la formación de Trabajo Social. Pensamiento Actual, 14(23), 41-50. https://dialnet.unirioja.es/ descarga/articulo/5821483.pdf

Hoyos Jover, A. M., \& Velásquez Arias, M. (2014). Lo ambiental como escenario emergente de intervención profesional para Trabajo Social. Universidad de Costa Rica. http://www.ts.ucr. ac.cr/binarios/pela/pl-000456.pdf

Liévano Latorre, A. (2013). Escenarios y perspectivas de trabajo social en ambiente. Trabajo Social. (15), 219-233. https://revistas.unal.edu.co/index.php/tsocial/article/view/42586/44139

Murillo Bonheví, D., \& Buckland, H. (2013). Antena de innovación social: vías hacia el cambio sistémico: ejemplos y variables para la Innovación Social. ESADE, Instituto de Innovación Social. 